\title{
砷对烤烟碳氮代谢及其产量和品质的影响
}

\author{
常思敏 马新明* 张贵龙 熊淑萍 詹克慧 刘国顺 \\ (河南农业大学 , 河南郑州 450002)
}

\begin{abstract}
摘 要 采用盆栽试验, 系统地研究了砷对烤烟全生育期的碳氮代谢及其产量和品质的影响。结果表明, 砷毒害 对烤烟全生育期的碳代谢有显著影响，抑制了碳的同化和转化，降低了整个生育期的叶绿素含量、光合速率，造成 了全生育期可溶性糖的积累, 导致了生育后期淀粉含量的降低, 最终使碳积累减少。砷毒害也改变了烤烟的氮代 谢, 造成生育前期氮同化能力的降低，表现出硝酸还原酶 (NR) 活性下降、总氮和蛋白质含量低于 $\mathrm{CK}$ 。砷毒害烤烟 的氮转化表现活跃, 提高了其中的游离氨基酸含量和谷氨酸-丙酮酸转氨酶 (GPT) 活性, 最终导致烤烟生育中后期 总氮和蛋白质的积累, 但使整个生育期的烟碱含量降低。研究还表明, 砷毒害降低了烤烟的产量和经济性状增加 了叶片中砷的积累, 可溶性总糖含量的提高和糖氮比的协调虽好, 但烟碱含量的降低和总氮、蛋白质含量的增加， 以及糖碱比和氮碱比的失调, 不利于碳氮代谢有关的化学品质形成。
\end{abstract}

关键词 砷 烤烟 碳代谢 氮代谢 产量 品质

\section{EFFECTS OF ARSENIC TOXICITY ON CARBON AND NITROGEN METABOLISM AND THE YIELD AND QUALITY OF FLUE-CURED TOBACCO}

\author{
CHANG Si-Min MA Xin-Ming ${ }^{*}$ ZHANG Gui-Long XIONG Shu-Ping ZHAN Ke-Hui and LIU Guo-Shun \\ ( Henan Agricultural University , Zhengzhou 450002 , China)
}

\begin{abstract}
Background and Aims Arsenic (As) exists ubiquitously in our environment and in various forms that can be harmful to human beings as well as agricultural crops. In order to study mechanisms of carbon and nitrogen metabolism in flue-cured tobacco, Nicotiana tabacum, contaminated by arsenic, a systematic experiment was conducted on the farm of Henan Agricultural University , Zhengzhou , China.

Methods Five arsenic treatment levels $\left(0,5,20,40,60 \mathrm{mg} \mathrm{kg}{ }^{-1}\right.$ (added as sodium arsenate $\mathrm{Na}_{3} \mathrm{AsO}_{4}$ $\left.12 \mathrm{H}_{2} \mathrm{O}\right)$ ) were used to determine the effects of arsenic toxicity on carbon and nitrogen metabolism and on the yield and quality of potted $(400 \mathrm{~mm} \times 340 \mathrm{~mm}$ ) flue-cured tobacco plants (Nicotiana tabacum L. cv.' Yunyan $85^{\prime}$ ).
\end{abstract}

Key Results The results showed that arsenic toxicity inhibited assimilation and transformation of carbon , decreased chlorophyll content and photosynthetic rates , and caused the accumulation of soluble sugar content during the whole growth period, and the decrease of starch content during the last part of the growing period. Arsenic toxicity also altered nitrogen metabolism and resulted in a decrease in nitrogen assimilation capacity during the early growing stage. Nitrate-reductase (NR) activity, and protein and total nitrogen content were decreased compared with the control. Nitrogen transformations resulted in an increase in the content of the free amino acids and activity of glutamate-pyruvate transaminase (GPT) , an accumulation of protein and total nitrogen during the middle and late growth stages, but a decrease in nicotine content during the whole growing period. The results also showed that arsenic toxicity lowered tobacco yields and their economic value , Although the sugar-nitrogen ratio and the increase of the total content of soluble sugars related to carbon-nitrogen metabolism was beneficial , the decrease of nicotine content and the increase of the content of protein and total nitrogen , as well as high sugar-nicotine and nitrogen-nicotine ratios were not favorable for the formation of leaves with high chemical quality.

Conclusions Arsenic toxicity had significant effects on carbon and nitrogen metabolism during the whole growing period, and lowered yield and economic value of flue-cured tobacco. Besides, it was unfavorable for the formation of leaves with high chemical quality, and led to an accumulation of arsenic in the leaves. Therefore, it was suggested that flue-cured tobacco not be planted in arsenic contamination regions.

Key words Arsenic , Flue-cured tobacco , Carbon metabolism , Nitrogen metabolism , Yield , Quality 
砷是土壤中和人类生活中的类金属污染物。砷 污染对农作物的毒害与人的生活和健康密切相关。 砷对农作物的毒害影响多有报道，但研究集中在积 累(Abedin et al., 2002 ; Carbonell-Barrachina et al. , 1997)、生长发育、产量和保护酶系统方面(Cox \& Kovar，2001; 李道林和程磊, 2000; 许嘉琳等，1993 杨 文婕和刘更另, 1997)。有关砷对碳氮代谢及其品质 的研究较少, 杨文婕和刘更另 (1997) 与许嘉琳等 (1993) 研究表明, 砷降低作物的叶绿素含量, Jha 和 Dubey (2004) 研究了 $\mathrm{As}_{2} \mathrm{O}_{3}$ 对水稻幼苗碳代谢的影 响 认为 $\mathrm{As}_{2} \mathrm{O}_{3}$ 导致水稻幼苗还原糖、非还原糖、可 溶性总糖含量增加，碳代谢紊乱。目前，砷对作物全 生育期碳氮代谢影响缺乏系统的研究,尤其是缺乏 砷对烤烟碳氮代谢及其产量和品质的影响研究。而 且, 国内外有关重金属对作物碳氮代谢的影响研究 结果也不尽一致(陈愚等,1998; 段昌群等,1994; Gouia et al. ,2004; 李素英等,1990 杨居荣等,1995； 周建华和王永锐, 1999)。本文研究了砷对烤烟碳氮 代谢及其产量和品质的影响, 旨在探索烤烟碳氮代 谢及其过程对砷毒害的响应, 以及砷对烤烟产量和 品质形成的利弊, 为烤烟生产提供理论依据，同时， 为进一步研究作物砷毒害的生理机制提供参考。

\section{1 材料和方法}

\section{1 试验材料及试验设计}

采用 $400 \mathrm{~mm} \times 340 \mathrm{~mm}$ 的聚乙烯花盆在河南农 业大学科教园区进行盆栽试验。供试土壤为壤质潮 土 耕层有机质含量 $8.50 \mathrm{~g} \mathrm{~kg}^{-1}$, 全氮含量 $0.89 \mathrm{~g}$ $\mathrm{kg}^{-1}$, 速效氮含量 $65.46 \mathrm{mg} \mathrm{kg}$ 责, 速效磷含量 24.42 $\mathrm{mg} \mathrm{kg}{ }^{-1}$, 速效钾含量 $108.00 \mathrm{mg} \mathrm{kg} \mathrm{kg}^{-1}$, 全砷含量 $7.188 \mathrm{mg} \mathrm{kg}^{-1}, \mathrm{pH}$ 值 7.8。以 $99 \%\left(\mathrm{NH}_{4}\right)_{2} \mathrm{SO}_{4} 、 99 \%$ $\mathrm{KNO}_{3}$ 和 $99.5 \% \mathrm{KH}_{2} \mathrm{PO}_{4}$ 作基肥, 施肥量为纯氮 0.2 $\mathrm{g} \mathrm{kg}^{-1}, \mathrm{~N}: \mathrm{P}_{2} \mathrm{O}_{5}: \mathrm{K}_{2} \mathrm{O}=1: 1.5: 3$ 。以砷 酸 钠 $\left(\mathrm{Na}_{3} \mathrm{AsO}_{4} \quad 12 \mathrm{H}_{2} \mathrm{O}\right)$ (北京化学试剂厂生产) 为污染源, 按纯砷含量计算, 设置 0 ( CK)、5、20、40 和 $60 \mathrm{mg}$ $\mathrm{kg}^{-1} 5$ 个处理。各处理于 2004 年 4 月 27 日随基肥 一起与风干过筛土混匀装盆, 每盆装土 $15 \mathrm{~kg}$ (为防 止污染扩散 装土时盆内套装塑料袋)。装盆后埋入 事先起好的垄中, 埋盆深度约为盆高的 $2 / 3$ 。宽窄 行单垄种植, 宽行 $120 \mathrm{~cm}$, 窄行 $80 \mathrm{~cm}$ 株距 $50 \mathrm{~cm}$ 。

供试烤烟品种为云烟 85' (Nicotiana tabacum L. cv.' Yunyan85') ,采用基质 $(V$ 草炭: $V$ 蛭石 : $V$ 珍珠岩 $=2: 1: 1)$ 穴盘育苗。2004 年 2 月 28 日洗种 摧芽，2004 日 3 月 7 日播种，定期随水浇灌烤烟育苗
专用肥，成苗后于 2004 年 5 月 5 日移栽入盆, 每盆 1 株, 各处理重复 18 盆, 完全随机排列。烤烟生长期 内各盆统一等量浇水, 并及时排除雨后盆内积水。

\section{2 测定项目及方法}

\subsection{1 碳代谢测定指标及方法}

叶绿素含量采用乙醇提取法测定 (赵世杰等， 1998）光合速率采用 LI-6400 便携式光合测定仪测 定, 可溶性糖和淀粉含量采用葸酮法测定 (赵世杰 等, 1998)。

\section{2 .2 氮代谢测定指标及方法}

总氮含量测定用过氧化氢-硫酸消化法 (王瑞新 等 2003) 烟碱含量测定用活性碳提取脱色法(王瑞 新等，2003）蛋白质含量采用间接计算法, 即蛋白质 $\left(\mathrm{g} \quad \mathrm{kg}^{-1}\right)=$ [全氮 $\left(\mathrm{g} \quad \mathrm{kg}^{-1}\right)$-烟碱氮 $\left.\left(\mathrm{g} \quad \mathrm{kg}^{-1}\right)\right] \times$ 6.25 游离氨基酸含量测定用狮三酮法(赵世杰等, 1998)，硝酸还原酶 (NR) 活性测定用活体法(赵世杰 等, 1998) , 谷氨酸-丙酮酸转氨酶 (GPT) 活性测定用 比色法(中国科学院上海植物生理研究所和上海市 植物生理学会, 1999)。

\subsection{3 取样时期}

叶绿素含量、可溶性糖含量、GPT 活性均于团棵 期(移栽后 $30 \mathrm{~d}$ )、现蕾期(移栽后 $55 \mathrm{~d}$ ) 和采收期(移 栽后 $85 \mathrm{~d}$ 即中部叶采收期，下同)测定。因客观原 因(如 NR 活性的测定需要光照诱导, 现蕾期 (3d 内)均为阴雨天等) ,仅测定团棵期、采收期的 NR 活 性和现蕾期和采收期的淀粉含量、游离氨基酸含量。 取样时, 各处理均选取生长一致的 3 棵烟株相同叶 位的叶片，用蒸馏水洗净后鲜样测定。蛋白质含量、 总氮含量和烟碱含量于团棵期、现蕾期、采收期取样 洗净后, 在烘箱中于 $105{ }^{\circ} \mathrm{C}$ 条件下杀青 $20 \mathrm{~min}$, 然后 在 $80{ }^{\circ} \mathrm{C}$ 条件下烘干至恒重, 采用干样测定。光合速 率于团棵期、现蕾期和采收期的上午9:00 11:00 测 定。

\section{2 .4 烘烤和产量、品质分析方法}

标记各处理有代表性的烟株 3 盆 叶片成熟后， 采用常规烘烤方法烘烤，以现行国家分级标准逐株 分级、计产，按 2004 年原烟收购价格计算单株产值、 均价和上中等烟比例。采用各处理烤后的中部叶进 行化学品质指标分析和砷含量的测定。可溶性总糖 (以下简 总糖”) 含量采用伯川法测定 (王瑞新等, 2003 ）总氮、烟碱、蛋白质含量的测定方法与上述氮 代谢的测定相同。砷含量的测定采用氢化物发生原子苂光光谱法(强卫国等 ,2003)。

\section{3 统计方法}


以处理为主区, 以测定的生育时期为副区, 运用 Excel 对碳氮代谢数据进行时间裂区设计方差分析。 采用 SPSS10.0 对产量和品质数据进行单因素方差 分析。多重比较采用 LSR 法。

\section{2 结果与分析}

\section{1 砷对烤烟碳代谢的影响}

\subsection{1砷对烤烟碳同化的影响}

叶绿素含量和光合速率是碳同化的两个重要生 理指标。砷对烤烟 3 个生育时期的叶绿素含量均有 一定的影响 (表 1)。团棵期的叶绿素含量随着土壤 中砷含量的增加而减小。现蕾期也呈现出类似的变 化趋势, 惟 $60 \mathrm{mg} \mathrm{kg}^{-1}$ 处理的叶绿素含量虽高于 20 和 $40 \mathrm{mg} \mathrm{kg}{ }^{-1}$ 两处理, 但仍低于 $\mathrm{CK}$ 。采收期的叶绿 素含量因土壤中砷含量增加的变化规律不明显, 但 施砷处理也均低于 CK。方差分析和多重比较的结 果表明, 除现蕾期 $5 \mathrm{mg} \mathrm{kg}{ }^{-1}$ 处理的叶绿素含量与 CK 差异显著外, 3个生育时期其余各施砷处理与 $\mathrm{CK}$ 间均达到了极显著差异。说明砷能严重降低烤 烟的叶绿素含量。

各时期光合速率的变化 (表 1 ) 表明,随土壤中 砷含量增加，团棵期光合速率在各处理间有明显降 低趋势 现蕾期和采收期处理间的降低趋势规律性
则不明显。除采收期 $5 \mathrm{mg} \mathrm{kg}$-1处理的光合速率略 高于同时期的 CK 外, 施砷处理在 3 个生育时期的 光合速率都低于 CK。这表明砷可降低烤烟的光合 速率。各时期处理间的方差分析表明，砷虽能降低 现蕾期的光合速率，但施砷处理与 CK 差异不显著， 而施砷能明显降低团棵期和采收期的光合速率。

\section{1 .2 砷对烤烟碳转化和积累的影响}

可溶性糖在碳运输转化代谢过程中具有重要作 用, 淀粉是碳代谢的最终结果, 因此, 可溶性糖含量 和淀粉含量可分别作为碳转化和碳积累的重要指 标。砷对烤烟碳转化和积累的影响结果见表 2 , 从表 2 可以看出, 施砷处理的可溶性糖含量在 3 个生育时 期都高于相应的 CK 除现蕾期 $60 \mathrm{mg} \mathrm{kg}^{-1}$ 处理与 CK 的差异不显著外，施砷处理与 CK 均达到了极显著差 异。说明砷造成了烤烟可溶性糖的大量积累。

对表 2 中两个生育时期的淀粉含量分析可以看 出, 除现蕾期 $60 \mathrm{mg} \mathrm{kg} \mathrm{kg}^{-1}$ 处理的淀粉含量极显著低 于 CK 外,施砷处理的淀粉含量都显著地高于 CK, 且随土壤中砷含量的增加, 淀粉含量变化明显, 5 $\mathrm{mg} \mathrm{kg}{ }^{-1}$ 处理时, 淀粉含量猛增至最高值, 20 和 40 $\mathrm{mg} \mathrm{kg}{ }^{-1}$ 处理的增加量减少。采收期淀粉含量的变 化与现蕾期结果相反, 施砷处理的淀粉含量均显著 地低于 CK, 导致砷对烤烟碳积累代谢的最终结果是

表 1 砷对烤烟叶绿素含量和光合速率的影响

Table 1 Effects of arsenic on chlorophyll content and photosynthetic rate in flue-cured tobacco

叶绿素含量

处理

Treatments $\left(\mathrm{mg} \mathrm{kg}^{-1}\right)$

对照 CK

5

20

40

60
Chlorophyll content ( $\left.\mathrm{mg} \mathrm{g}^{-1} \mathrm{FW}\right)$

$\begin{array}{ccc}\begin{array}{c}\text { 团棵期 } \\ \text { Rosette stage }\end{array} & \begin{array}{c}\text { 现蕾期 } \\ \text { Budding stage }\end{array} & \begin{array}{c}\text { 采收期 } \\ \text { Harvest stage }\end{array} \\ 2.729^{\mathrm{aA}} & 1.497^{\mathrm{aA}} & 0.725^{\mathrm{aA}} \\ 2.198^{\mathrm{bB}} & 1.486^{\mathrm{bA}} & 0.554^{\mathrm{EE}} \\ 1.657^{\mathrm{cC}} & 1.300^{\mathrm{dC}} & 0.682^{\mathrm{cC}} \\ 1.515^{\mathrm{dD}} & 1.119^{\mathrm{eD}} & 0.642^{\mathrm{dD}} \\ 0.925^{\mathrm{eE}} & 1.334^{\mathrm{cB}} & 0.704^{\mathrm{bB}}\end{array}$

光合速率

Photosynthetic rate $\left(\mu \mathrm{mol} \mathrm{m} \mathrm{m}^{-2} \mathrm{~s}^{-1}\right)$

\begin{tabular}{ccc}
$\begin{array}{c}\text { 团棵期 } \\
\text { Rosette stage }\end{array}$ & $\begin{array}{c}\text { 现蕾期 } \\
\text { Budding stage }\end{array}$ & $\begin{array}{c}\text { 采收期 } \\
\text { Harvest stage }\end{array}$ \\
\hline $9.34^{\mathrm{aA}}$ & $9.49^{\mathrm{NS}}$ & $4.01^{\mathrm{abA}}$ \\
$8.36^{\mathrm{abA}}$ & $9.48^{\mathrm{NS}}$ & $5.05^{\mathrm{aA}}$ \\
$7.45^{\mathrm{bB}}$ & $8.49^{\mathrm{NS}}$ & $3.56^{\mathrm{bA}}$ \\
$6.84^{\mathrm{bcB}}$ & $9.41^{\mathrm{NS}}$ & $1.58^{\mathrm{cB}}$ \\
$6.74^{\mathrm{cB}}$ & $8.45^{\mathrm{NS}}$ & $1.63^{\mathrm{cB}}$ \\
\hline
\end{tabular}

表中小写字母表示 0.05 的差异显著性水平, 大写字母表示 0.01 的差异显著性水平。NS 和同一列中字母相同者, 表示处理间差异不显著 Small letters mean significance at 0.05 levels. Capital letters mean significance at 0.01 levels. NS and the same letters mean no significance in the line

表 2 砷对烤烟可溶性糖和淀粉含量的影响

Table 2 Effects of arsenic on the content of soluble sugar and starch in flue-cured tobacco

\begin{tabular}{|c|c|c|c|c|c|}
\hline \multirow{2}{*}{$\begin{array}{c}\text { 处理 } \\
\text { Treatments }\left(\mathrm{mg} \mathrm{kg}^{-1}\right)\end{array}$} & \multicolumn{3}{|c|}{$\begin{array}{c}\text { 可溶性糖含量 } \\
\text { Soluble sugar content }\left(\mu \mathrm{g} \mathrm{g}^{-1} \mathrm{FW}\right)\end{array}$} & \multicolumn{2}{|c|}{$\begin{array}{c}\text { 淀粉含量 } \\
\text { Starch content }\left(\mu \mathrm{g} \mathrm{g}^{-1} \mathrm{FW}\right)\end{array}$} \\
\hline & $\begin{array}{c}\text { 团棵期 } \\
\text { Rosette stage }\end{array}$ & $\begin{array}{c}\text { 现蕾期 } \\
\text { Budding stage }\end{array}$ & $\begin{array}{c}\text { 采收期 } \\
\text { Harvest stage }\end{array}$ & $\begin{array}{c}\text { 现蕾期 } \\
\text { Budding stage }\end{array}$ & $\begin{array}{c}\text { 采收期 } \\
\text { Harvest stage }\end{array}$ \\
\hline 对照 CK & $4.909^{\mathrm{bB}}$ & $14.900^{\mathrm{dD}}$ & $12.940^{\mathrm{bB}}$ & $59.368^{\mathrm{bB}}$ & $49.270^{\mathrm{aA}}$ \\
\hline 5 & $12.042^{\mathrm{aA}}$ & $18.349^{\mathrm{bcBC}}$ & $18.535^{\mathrm{aA}}$ & $70.795^{\mathrm{aA}}$ & $41.885^{\mathrm{bAB}}$ \\
\hline 20 & $10.138^{\mathrm{aA}}$ & $21.549^{\mathrm{aAB}}$ & $17.329^{\mathrm{aA}}$ & $66.513^{\mathrm{aA}}$ & $30.382^{\mathrm{cC}}$ \\
\hline 40 & $9.969^{\mathrm{aA}}$ & $22.337^{\mathrm{aA}}$ & $17.128^{\mathrm{aA}}$ & $65.261^{\mathrm{abAB}}$ & $31.980^{\mathrm{cBC}}$ \\
\hline 60 & $9.742^{\mathrm{aA}}$ & $16.218^{\mathrm{cdCD}}$ & $16.631^{\mathrm{aA}}$ & $38.925^{\mathrm{cC}}$ & $18.977^{\mathrm{dD}}$ \\
\hline
\end{tabular}


碳的积累减少。

\section{2 砷对烤烟氮代谢的影响}

\subsection{1 砷对烤烟氮同化的影响}

总氮含量是烤烟同化环境中氮素的最终结果， 既是氮积累的生理指标, 又是氮同化的生理指标。 砷对烤烟总氮含量的影响见表 3。由表 3 可以看 出, 施砷处理的总氮含量与 CK 相比, 生育时期间的 变化较大。砷降低了团棵期的总氮含量, 并随土壤 中砷含量的增加而减少。现蕾期的总氮含量则随土 壤中砷含量的增加而增加或显著增加，采收期除 40 $m g \mathrm{~kg}^{-1}$ 处理显著低于 CK 外, 其它施砷处理与 CK
基本持平或显著增加。

硝酸还原酶 (NR) 是烤烟氮同化过程中一个关 键的调节酶和限速酶。对两个生育时期的 NR 活性 分析(表 3)表明，砷能造成团棵期 NR 活性的降低， 而且土壤中砷含量越高, 降低越显著。采收期各处 理的 NR 活性有高有低。其中原因有待于进一步试 验。

综合以上分析认为, 砷抑制烤烟生长早期氮的 同化,而使生长中后期氮的同化量增加。

\subsection{2 砷对烤烟氮转化的影响}

氨基酸是合成蛋白质的主要原料，也是蛋白质

表 3 砷对烤烟总氮含量和 NR 活性的影响

Table 3 Effects of arsenic on total nitrogen content and NR activity in flue-cured tobacco

\begin{tabular}{|c|c|c|c|c|c|}
\hline \multirow{2}{*}{$\begin{array}{c}\text { 处理 } \\
\text { Treatments }\left(\mathrm{mg} \mathrm{kg}^{-1}\right)\end{array}$} & \multicolumn{3}{|c|}{$\begin{array}{c}\text { 总氮含量 } \\
\text { Total nitrogen content }\left(\mathrm{g} \mathrm{kg}^{-1} \mathrm{DW}\right)\end{array}$} & \multicolumn{2}{|c|}{$\begin{array}{c}\text { NR 活性 } \\
\text { NR activity }\left(\mu \mathrm{g} \mathrm{g}^{-1} \mathrm{FW} \mathrm{h} \mathrm{h}^{-1}\right)\end{array}$} \\
\hline & $\begin{array}{c}\text { 团棵期 } \\
\text { Rosette stage }\end{array}$ & $\begin{array}{c}\text { 现蕾期 } \\
\text { Budding stage }\end{array}$ & $\begin{array}{c}\text { 采收期 } \\
\text { Harvest stage }\end{array}$ & $\begin{array}{c}\text { 现蕾期 } \\
\text { Budding stage }\end{array}$ & $\begin{array}{c}\text { 采收期 } \\
\text { Harvest stage }\end{array}$ \\
\hline 对照 CK & $13.637^{\mathrm{aA}}$ & $7.933^{\mathrm{cB}}$ & $6.067^{\mathrm{bA}}$ & $0.994^{\mathrm{aA}}$ & $0.524^{\text {bcBC }}$ \\
\hline 5 & $13.015^{\mathrm{abA}}$ & $11.200^{\mathrm{aA}}$ & $6.066^{\mathrm{bA}}$ & $0.983^{\mathrm{aA}}$ & $0.348^{\mathrm{dD}}$ \\
\hline 20 & $12.081^{\mathrm{bA}}$ & $9.178^{\mathrm{bB}}$ & $7.000^{\mathrm{aA}}$ & $0.463^{\mathrm{bB}}$ & $0.573^{\mathrm{bB}}$ \\
\hline 40 & $7.622^{\mathrm{cB}}$ & $11.200^{\mathrm{aA}}$ & $4.200^{\mathrm{cB}}$ & $0.399^{\mathrm{bB}}$ & $0.726^{\mathrm{aA}}$ \\
\hline 60 & $7.911^{\mathrm{cB}}$ & $11.822^{\mathrm{aA}}$ & $7.637^{\mathrm{aA}}$ & $0.279^{\mathrm{cC}}$ & $0.457^{\mathrm{cCD}}$ \\
\hline
\end{tabular}

表注同表 1 Notes see Table 1

降解的主要产物。GPT 催化谷氨酸和丙酮酸可逆地 转化为丙氨酸和 $\alpha$-酮戊二酸之间的氨基转移反应, GPT 在氨基酸的合成和蛋白质的分解代谢中起重要 的中介作用，GPT 活性增加，表明氨基酸代谢旺盛， 蛋白质分解下降, 而合成代谢加强。用游离氨基酸 含量和 GPT 活性可部分反映氮转化的生理变化。 从图 1 可以看出 现蕾期和采收期的游离氨基酸含 量均有随土壤砷含量的增加而递增的趋势, 3 个生 育时期的 GPT 活性的变化也有类似的结果 (图 2)。 但两个生育时期的游离氨基酸含量差异不明显, GPT 活性在采收期的增加趋势尤其明显。由此可 见, 砷能增加烤烟中的游离氨基酸积累, 并促使氮的 转化向蛋白质合成的方向发展。

\subsection{3 砷对烤烟蛋白质和烟碱含量的影响}

蛋白质和烟碱是烤烟有机氮合成中的两个重要 生理指标。砷对烤烟蛋白质含量的影响与对总氮含 量的影响一致 (表 4)。降低了烤烟团棵期的蛋白质 含量、随土壤中砷含量的增加, 降低趋势愈加明显。 现蕾期施砷则显著地增加烤烟蛋白质含量。除 40 $\mathrm{mg} \mathrm{kg}{ }^{-1}$ 处理采收期的蛋白质含量异常外, 其它砷处 理也造成烤烟采收期的蛋白质含量增加。

烟碱是烟草特有的含氮化合物，对烟草品质的

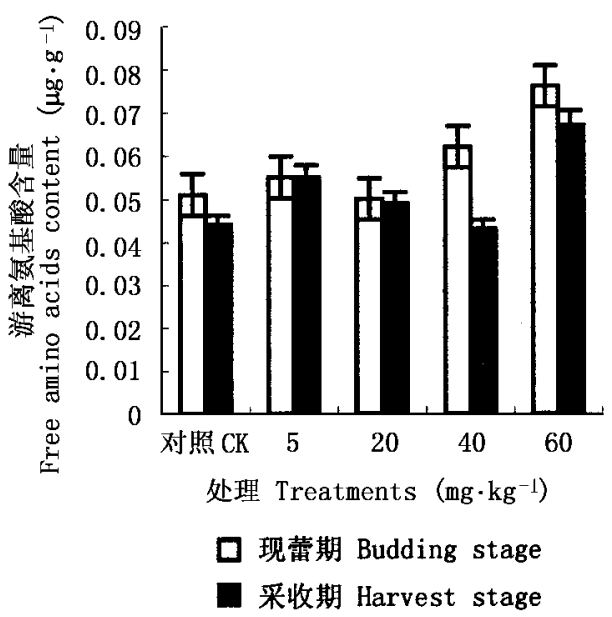

图 1 砷对烤烟游离氨基酸含量的影响

Fig. 1 Effects of arsenic on free amino acid content in flue-cured tobacco

形成具有重要作用。但烟碱含量和蛋白质含量的变 化不同(表 4)。从表 4 可以看出, 施砷处理的烟碱 含量都低于 CK, 除现蕾期 $20 \mathrm{mg} \mathrm{kg}{ }^{-1}$ 的烟碱碱含量 稍高于 $5 \mathrm{mg} \mathrm{kg}^{-1}$ 外, 随土壤中砷含量的增加, 烟碱 含量均随之降低, 且砷含量越高, 降低幅度越显著。

\section{3 砷对烤烟产量和经济性状的影响}

砷对烤烟碳氮代谢的影响最终反映在对其产量 
表 4 砷对烤烟蛋白质和烟碱含量的影响

Table 4 Effects of arsenic on the content of protein and nicotine in flue-cured tobacco

\begin{tabular}{|c|c|c|c|c|c|c|}
\hline \multirow{2}{*}{$\begin{array}{c}\text { 处理 } \\
\text { Treatments }\left(\mathrm{mg} \mathrm{kg}^{-1}\right)\end{array}$} & \multicolumn{3}{|c|}{$\begin{array}{c}\text { 蛋白质含量 } \\
\text { Protein content }\left(\mathrm{g} \mathrm{kg}^{-1} \mathrm{DW}\right) \\
\end{array}$} & \multicolumn{3}{|c|}{$\begin{array}{c}\text { 烟碱含量 } \\
\text { Nicotine content }\left(\mathrm{g} \mathrm{kg}^{-1} \mathrm{DW}\right)\end{array}$} \\
\hline & $\begin{array}{c}\text { 团棵期 } \\
\text { Rosette stage }\end{array}$ & $\begin{array}{c}\text { 现蕾期 } \\
\text { Budding stage }\end{array}$ & $\begin{array}{c}\text { 采收期 } \\
\text { Harvest stage }\end{array}$ & $\begin{array}{c}\text { 团棵期 } \\
\text { Rosette stage }\end{array}$ & $\begin{array}{c}\text { 现蕾期 } \\
\text { Budding stage }\end{array}$ & $\begin{array}{c}\text { 采收期 } \\
\text { Harvest stage }\end{array}$ \\
\hline 对照 CK & $83.742^{\mathrm{aA}}$ & $45.879^{\mathrm{cB}}$ & $33.092^{\mathrm{bB}}$ & $0.238^{\mathrm{a}}$ & $0.593^{\mathrm{aA}}$ & $0.772^{\text {aA }}$ \\
\hline 5 & $79.390^{\mathrm{abA}}$ & $66.396^{\mathrm{aA}}$ & $33.473^{\mathrm{bB}}$ & $0.312^{\mathrm{ab}}$ & $0.577^{\mathrm{aA}}$ & $0.710^{\mathrm{aA}}$ \\
\hline 20 & $74.221^{\mathrm{bA}}$ & $53.681^{\mathrm{bB}}$ & $41.206^{\mathrm{aAB}}$ & $0.206^{\mathrm{b}}$ & $0.589^{\mathrm{aA}}$ & $0.407^{\mathrm{bB}}$ \\
\hline 40 & $46.619^{\mathrm{cB}}$ & $66.477^{\mathrm{aA}}$ & $24.417^{\mathrm{cB}}$ & $0.163^{\mathrm{b}}$ & $0.564^{\mathrm{aA}}$ & $0.293^{\mathrm{cB}}$ \\
\hline 60 & $48.617^{\mathrm{cB}}$ & $71.761^{\mathrm{aA}}$ & $46.065^{\mathrm{aA}}$ & $0.132^{\mathrm{b}}$ & $0.340^{\mathrm{bB}}$ & $0.266^{\mathrm{eB}}$ \\
\hline
\end{tabular}

表注同表 1 Notes see Table 1

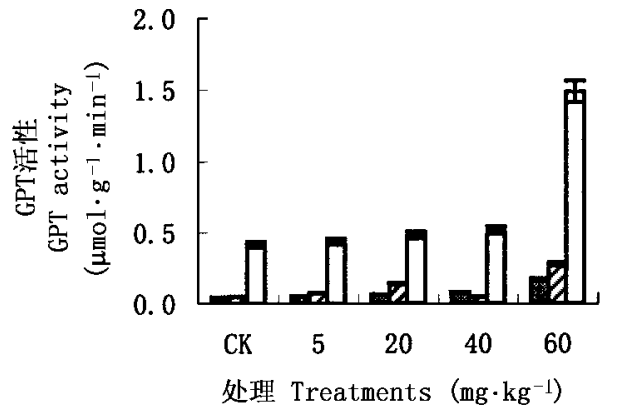

团棵期 Rosette stage

巴现蕾期 Budding stage 口采收期 Harvest stage

图 2 砷对烤烟 GPT 活性的影响

Fig.2 Effects of arsenic on GPT activity in flue-cured tobacco

和品质的影响上。砷对烤烟产量和经济性状的影响 非常明显 (表 5)。从表 5 可以看出, 随着土壤中砷 含量的增加, 烤烟的单株产量依次降低, 且降低幅度 越来越大。施砷处理的单株产值、均价、上中等烟比 例都低于 CK。40 和 $60 \mathrm{mg} \mathrm{kg}^{-1}$ 处理的均价虽然高 于较低施砷处理, 但因产量下降极显著，上中等烟中 上等烟的比例几乎为零 致使最终的综合性状较差。

\section{4 砷对烤烟化学品质及砷含量的影响}

对烤烟中部叶中砷含量以及与碳氮代谢有关的 化学品质指标进行分析结果表明，砷对烘烤后烤烟 的化学品质影响较大 (表 6)。从表 6 可以看出, 施 砷处理的烤烟中砷含量都极显著地高于 CK, 且随着 施砷量的增加，总砷含量极显著地增加。除 $40 \mathrm{mg}$ $\mathrm{kg}^{-1}$ 处理的总氮和蛋白质含量低于 CK, 差异不显著 以外, 施砷处理的总糖、总氮和蛋白质含量均高于 CK。方差分析表明, 砷对可溶性糖含量和蛋白质含 量的影响较大, 与 CK 达到了极显著差异。施砷有 降低烤烟烟碱含量的趋势, $5 \mathrm{mg} \mathrm{kg}{ }^{-1}$ 处理与 CK 差 异不显著, 其它处理的降低趋势则越来越明显。砷 对这些化学品质指标的影响与上述采收期对应的碳
氮代谢指标的影响一致。

总氮、蛋白质含量的提高和烟碱含量的降低，会 导致烤烟的刺激性增大，吸食味不良，劲头不足(王 瑞新等 2003)。在一定范围内, 烤烟总糖含量的提 高有利于其品质, 但总糖含量应和总氮、烟碱和蛋白 质含量结合起来考察 糖氮、氮碱之间保持适当的比 例才符合优质烟的要求(王瑞新等,2003)。从表 6 可知, 砷能使烤烟的糖碱比、氮碱比和施木克(总糖/ 蛋白质) 值增加。施木克值的增加似乎有利于协调 糖氮比。但糖碱比和氮碱比的增加, 来源于总糖含 量和总氮含量的增加和烟碱含量的降低, 这更加大 了糖碱比和氮碱比的不协调性, 势必造成烤烟刺激 性加大，吸食味不良等。

\section{3 结论与讨论}

1) 砷在土壤中的存在形态决定着砷对生物的 有效性和毒性(陈同斌, 1996;Pongratz，1998)。土壤 中砷以无机态为主, 而无机态砷又以 $\mathrm{As}(V)$ 为主 (王 春旭等, 1993) ,土壤中的 As (V) 和 As (III) 之间可以 通过氧化-还原反应而发生价态转变，二者之间保持 动态平衡( 陈同斌,1996; Manning \& Suarez,2000)。 因此, 本研究采用含无机态 As $(V)$ 的砷酸钠 $\left(\mathrm{Na}_{3} \mathrm{AsO}_{4} \quad 12 \mathrm{H}_{2} \mathrm{O}\right)$ 为土壤污染源进行试验。

2) 碳氮代谢是作物最基本的生理代谢，碳氮代 谢的强度、生长发育过程中的动态变化对作物的产 量和品质形成将产生重大影响。烤烟碳代谢包括无 机碳在叶绿体中通过光合作用转化为有机碳的同化 代谢, 磷酸丙糖通过叶绿体膜运至细胞质合成蔗糖 并进一步转化为单糖的碳水化合物运输转化代谢和 以淀粉积累为主要标志的碳积累代谢等 3 个阶段 (史宏志和韩锦峰, 1998)。本试验研究结果表明, 砷 对烤烟碳代谢有显著影响, 可引起烤烟整个生育期 的叶绿素含量、光合速率降低，从而抑制了烤烟对无 机碳的同化。这一结果与其它重金属对作物碳代谢 
表 5 砷对烤烟产量和经济性状的影响

Table 5 Effects of arsenic on yield and economic properties of flue-cured tobacco

\begin{tabular}{ccccc}
\hline $\begin{array}{c}\text { 处理 } \\
\text { Treatment }\left(\mathrm{mg} \mathrm{kg}^{-1}\right)\end{array}$ & $\begin{array}{c}\text { 单株产量 } \\
\text { Yield per plant }(\mathrm{g})\end{array}$ & $\begin{array}{c}\text { 单株产值 } \\
\text { Value per plant }(\text { yuan })\end{array}$ & $\begin{array}{c}\text { 均价 } \\
\text { 上中等烟比例 } \\
\text { Average price }\left(\text { yuan } \mathrm{kg}^{-1}\right)\end{array}$ & $\begin{array}{c}\text { Ratio of high level }(\%) \\
\text { 对照 } \mathrm{CK}\end{array}$ \\
5 & $109.02^{\mathrm{aA}}$ & $0.760^{\mathrm{aA}}$ & $6.953^{\mathrm{a}}$ & $91.58^{\mathrm{aA}}$ \\
20 & $104.75^{\mathrm{aA}}$ & $0.576^{\mathrm{bB}}$ & $5.499^{\mathrm{b}}$ & $79.04^{\mathrm{bcB}}$ \\
40 & $103.68^{\mathrm{bA}}$ & $0.529^{\mathrm{bB}}$ & $5.102^{\mathrm{b}}$ & $82.01^{\mathrm{bcB}}$ \\
60 & $88.49^{\mathrm{bB}}$ & $0.538^{\mathrm{bB}}$ & $5.741^{\mathrm{ab}}$ & $78.69^{\mathrm{bcB}}$ \\
\hline
\end{tabular}

表注同表 1 Notes see Table 1

表 6 砷对烤烟化学品质及砷含量的影响

Table 6 Effects of arsenic on chemical quality and arsenic content of flue-cured tobacco

\begin{tabular}{|c|c|c|c|c|c|c|c|c|}
\hline $\begin{array}{c}\text { 处理 } \\
\text { Treatment } \\
\left(\mathrm{mg} \mathrm{kg}^{-1}\right)\end{array}$ & $\begin{array}{c}\text { 总砷含量 } \\
\text { Total As } \\
\text { content } \\
\left(\mathrm{mg} \mathrm{kg}^{-1}\right)\end{array}$ & $\begin{array}{c}\text { 总糖含量 } \\
\text { Total sugar } \\
\text { content } \\
(\mathrm{TS}) \\
\left(\mathrm{g} \mathrm{kg}^{-1}\right)\end{array}$ & $\begin{array}{c}\text { 总氮含量 } \\
\text { Total } \\
\text { nitrogen } \\
\text { content } \\
(\mathrm{TN}) \\
\left(\mathrm{g} \mathrm{kg}^{-1}\right)\end{array}$ & $\begin{array}{c}\text { 烟碱含量 } \\
\text { Nicotine } \\
\text { content } \\
\left(\mathrm{Nico}^{2}\right) \\
\left(\mathrm{g} \mathrm{kg}^{-1}\right)\end{array}$ & $\begin{array}{c}\text { 蛋白质含量 } \\
\text { Protein } \\
\text { content } \\
(\text { Pro }) \\
\left(\mathrm{g} \mathrm{kg}^{-1}\right)\end{array}$ & $\begin{array}{l}\text { 糖碱比 } \\
\text { TS/Nico }\end{array}$ & $\begin{array}{l}\text { 氮碱比 } \\
\text { TN/Nico }\end{array}$ & $\begin{array}{c}\text { 施木克值 } \\
\text { TS/Pro }\end{array}$ \\
\hline 对照 CK & $0.712^{\mathrm{aA}}$ & $16.543^{\mathrm{bB}}$ & $4.900^{\mathrm{b}}$ & $0.642^{\mathrm{aA}}$ & $26.611^{\mathrm{bcB}}$ & $25.763^{\mathrm{bB}}$ & $7.627^{\mathrm{cB}}$ & $0.607^{\mathrm{b}}$ \\
\hline 5 & $2.538^{\mathrm{bB}}$ & $19.724^{\mathrm{aA}}$ & $5.431^{\mathrm{a}}$ & $0.743^{\mathrm{aA}}$ & $29.300^{\mathrm{abA}}$ & $31.196^{\mathrm{bB}}$ & $8.591^{\mathrm{bcB}}$ & $0.674^{\mathrm{b}}$ \\
\hline 20 & $7.595^{\mathrm{cC}}$ & $18.896^{\mathrm{aA}}$ & $5.367^{\mathrm{a}}$ & $0.534^{\mathrm{bA}}$ & $30.202^{\mathrm{abA}}$ & $33.302^{\mathrm{bB}}$ & $10.137^{\mathrm{bcB}}$ & $0.593^{\mathrm{b}}$ \\
\hline 40 & $12.614^{\mathrm{dD}}$ & $19.342^{\mathrm{aA}}$ & $4.122^{\mathrm{b}}$ & $0.364^{\mathrm{cB}}$ & $23.488^{\mathrm{cB}}$ & $58.560^{\mathrm{aA}}$ & $11.558^{\mathrm{bB}}$ & $0.925^{\mathrm{a}}$ \\
\hline 60 & $20.557^{\mathrm{eE}}$ & $19.525^{\mathrm{aA}}$ & $5.522^{\mathrm{a}}$ & $0.297^{\mathrm{cB}}$ & $32.656^{\mathrm{aA}}$ & $66.390^{\mathrm{aA}}$ & $18.229^{\mathrm{aA}}$ & $0.605^{\mathrm{b}}$ \\
\hline
\end{tabular}

表注同表 1 Notes see Table 1

的有关研究相一致(陈愚等, 1998; 杨居荣等,1995； 周建华和王永锐，1999）。烤烟的可溶性糖包括葡萄 糖、果糖等单糖和蔗糖、麦芽糖等二糖, 以及低聚度 的棉子糖等，因此，可溶性糖含量是烤烟碳转化代谢 的重要指标。本试验研究发现, 砷提高了烤烟整个 生育期的可溶性糖含量, 这与 Jha 和 Dubey (2004) 对 砷影响水稻 (Oryza sativa) 的可溶性糖含量结论一 致，与杨居荣等 (1995)、周建华和王永锐 (1999) 对镉 影响作物可溶性糖含量的研究结果相反。其中原因 可能是不同重金属对作物碳转化的影响不同，具体 原因有待于进一步试验。据 Jha 和 Dubey (2004) 对 砷造成水稻幼苗 $\alpha$-淀粉酶、 $\beta$-淀粉酶活性下降的研 究结论, 可溶性糖含量的增加, 可能不是淀粉分解的 结果，由此可以推断砷抑制了烤烟中碳向淀粉合成 方向的转化。砷能提高现蕾期烤烟的淀粉含量, 降 低其采收期的含量, 最终造成碳积累减少。需要说 明的是 现蕾期可溶性糖的积累和淀粉含量的提高 似乎是矛盾的 其中原因尚需进一步研究。总之 本 研究对 3 个生育时期碳代谢的系统研究表明, 砷毒 害严重影响了烤烟全生育期的碳代谢。

3) 烤烟的氮代谢包括无机氮的还原、同化及有 机含氮化合物的转化、合成等过程 (史宏志和韩锦 峰, 1998)。本研究表明, 砷对烤烟的氮代谢也产生 着显著影响，导致其团棵期 NR 活性下降、总氮和蛋 白质含量降低，抑制了烤烟生长前期氮的还原和同 化。随着烤烟抗砷毒害能力的增强, 现蕾期以后, 砷
又使烤烟的总氮含量和蛋白质含量明显增加，最终 导致烤烟体内氮的积累。也正因为如此，烤烟体内 向有机氮合成方向转化的代谢旺盛，造成游离氨基 酸、总氮和蛋白质的积累。砷影响烟草特有烟碱含 量的结果表明，砷能降低烤烟整个生育期的烟碱含 量, 且土壤中砷含量越高, 烟碱含量降低越明显。

4) 本试验研究还表明, 砷能显著降低烤烟产量 和产值等经济性状, 造成其叶中砷的大量积累, 又使 其碳氮代谢有关的化学品质指标发生较大变化, 造 成总糖、总氮和蛋白质含量增加, 烟碱含量下降。由 于本试验为盆栽砷毒害试验, 烤烟生长环境较差, 单 从化学品质绝对数值的变化来看, 难以判断砷毒害 对烤烟品质影响的优劣。从糖氮比例和氮碱比例的 协调性来看，砷造成烤烟施木克值的增加，虽有利于 糖氮比例的协调，但糖碱比、氮碱比的增加，又使二 者的协调性更差，况且，施木克值在评价品质方面存 在一定的局限性。本研究综合分析后认为, 总糖、总 氮和蛋白质含量的增加, 烟碱含量的降低, 糖碱比和 氮碱比的失调，说明砷毒害不利于烤烟与碳氮代谢 有关的化学品质的形成。更为严重的是, 砷造成的 烤烟体内砷的大量积累，会极大地危害吸烟者的健 康。

5) 常思敏等 (2005) 对砷研究的有关文献综述 后认为, 砷对作物生理毒害的机理存在两种学说, 即 颈基结合学说和离子拮抗学说。两种学说都认为砷 能抑制光合作用有关的酶活性，这是砷降低烤烟碳 
同化的主要原因。砷造成烤烟 NR 活性的降低也可 从颈基结合学说中得到解释, 硝酸还原酶是氮同化 过程中一个关键的调节酶和限速酶, 也是含琉基酶 （陈愚等,1998），砷与其颈基结合，抑制其活性。另 外, 黄玉山等 (1992)、Steffens (1990) 发现 $\mathrm{AsO}_{4}{ }^{3}$-能诱 导植物络合素 (Phytochelatin , PC) 合成, PC 是含有 琉基的非蛋白质多肽, 能螯合金属离子形成无毒或 低毒络合物。这可能是本研究中烤烟生育中后期总 氮和蛋白质含量增加的主要原因之一。

6) 至于已有研究认为的土壤中含有极微量砷 时对作物的生长发育有刺激作用(陈同斌和刘更另, 1993 ) 本研究的结果不明显, 可能与供试土壤中原 有的砷含量较高有关。另外, 本试验为盆栽试验 结 果有待于大田验证, 但仍建议砷污染地区种植烤烟 要慎重考虑。

\section{参 考 文 献}

Abedin MJ, Feldmann J, Meharg AA (2002). Uptake kinetics of arsenic species in rice plants. Plant Physiology Preview, 128, $1120-1128$.

Carbonell-Barrachina A, Burló-Carbonell F, Mataix-Beneyto J (1997). Effect of sodium arsenite on arsenic accumulation and distribution in leaves and fruit of Vitis vinifera. Journal of Plant Nutrition, 20,379-387.

Chang SM(常思敏), Ma XM(马新明), Jiang YY(蒋媛媛), He DX(贺德先), Zhang GL(张贵龙) (2005). Research progress on arsenic contamination in soil and arsenic toxicity in crops. Journal of Henan Agricultural University (河南农业大学学 报),39, 161 - 166. (in Chinese with English abstract)

Chen TB(陈同斌) (1996). Arsenic in soil solution and its effect on the growth of rice (Oryza sativa L.). Acta Ecologica Sinica (生 态学报), 16, 147 - 153. (in Chinese with English abstract)

Chen TB(陈同斌), Liu GL(刘更另) (1993). Effect of Arsenic on rice (Oryza sativa L.) growth and development and its mechanism. Scientia Agricultura Sinica (中国农业科学), 26(6), 50 - 58. (in Chinese with English abstract)

Chen Y(陈愚), Ren JC(任久长), Cai XM(蔡晓明) (1998). Effects of Cadmium on nitrate reductase and speroxide dimutase of submerged macrophytes. Acta Scientiae Circumstantiae (环境科 学学报), 18,313-317. (in Chinese with English abstract)

Cox MS, Kovar JL(2001). Soil arsenic effects on canola seedling growth and iron uptake. Communications in Soil Science and Plant Analysis, 32, $107-117$.

Duan CQ(段昌群), Wang HX(王焕校)，Hu B(胡斌)（1994）。 Interactions between cadmium and iron and their effects on the quality of tobacco. Journal of Yunan University (Natural Sciences Edition) (云南大学学报 (自然科学版) ), 16, 257 - 261. (in Chinese with English abstract)

Gouia H, Suzuki A, Brulfert J, Ghorbal MH(2003) . Effect of cadmium on the coordination of nitrogen and carbon metabolism in bean seedlings. Journal of Plant Physiology, 160, 367 - 375

Huang YS (黄玉山), Chen JM (陈建敏), Tan FY (谭凤仪) (1992). Current research on heavy metal binding complexes of plants. Acta Botanica Sinica (植物学报), 34, 146 - 158. (in Chinese with English abstract)
Jha AB, Dubey RS (2004) . Carbohydrate metabolism in growing rice seedlings under arsenic toxicity. Journal of Plant Physiolo$g y, 16,867-872$.

Li DL (李道林), Cheng L (程否) (2000). Distribution of As forms in soils and biological effect of As on Chinese cabbage (Brassica chinensis L. ). Journal of Anhui Agricultural University (安徽农业大学学报), 27, 131 - 134. (in Chinese with English abstract)

Li SY (李素英), Wang HX(王焕校)，Wu YS(吴玉树) (1990). Effects of pollution from lead cadmium, zinc and their different combinations on the quality of tobacco. China Environmental Science (中国环境科学) , 10,457-460. (in Chinese with English abstract)

Manning A, Suarez DL (2000). Modeling arsenic ( III ) adsorption and heterogeneous oxidation kinetics in soils. Soil Science Society of America Journal, 64, 128 - 137.

Pongratz R(1998). Arsenic speciation in environmental samples of contaminated soil. The Science of the Total Environment, 224, $133-141$.

Qiang WG (强卫国), Yang HF (杨慧芬), Mao H (毛红) (2003). Delermination of Total Arsenic and Abio-arsenic in Foods (食品中总砷和无机砷的测定). Standards Press of China, Beijing. (in Chinese)

Shanghai Institute of Plant Physiology, the Chinese Academy of Sciences (中国科学院上海植物生理研究所), Shanghai Society for Plant Physiology (上海市植物生理学会) (1999). Modern Plant Physiology Experiment Guide (现代植物生理学实验指 南). Science Press, Beijing. (in Chinese)

Shi HZ(史宏志), Han JF (韩锦峰) (1998). Several problems on carbon and nitrogen metabolism in flue-cured tobacco. Tobacco Science \& Technology (烟草科技)，(2), 34-36. (in Chinese)

Steffens JC (1990). The heavy metal-binding peptides of plants. Annual Review of Plant Physiology and Plant Moleculer Biology, $41,553-575$.

WANG RX (王瑞新), Han F G (韩富根), LU H (卢红) (2003). Tobacco Chemistry (烟草化学). China Agriculture Press, Beijing. (in Chinese)

Wang CX(王春旭), Li SZ(李生志), Xu RY(许荣玉)（1993）. A study on existing forms of arsenic in environment. Environmental Science (环境科学) , 14(4), 53-57. (in Chinese)

Xu JL (许嘉琳), Yang JR (杨居荣), Jing HW (荆红卫) (1993). Effects of arsenic contamination on crops and their factors. Soil (土壤), 26(6), 50-58. (in Chinese)

Yang JR (杨居荣), He JQ (贺建群), Jiang WR (蒋婉茹) (1995). Effect of Cd pollution on the physiology and biochemistry of plant. Agro-environmental Protection(农业环境保护), 14, 193 - 197. (in Chinese with English abstract)

Yang WJ(杨文婕)，Liu GL(刘更另) (1997). Effect of arsenate on plant decrepit. Plant Physiology Communications (植物生理 学通讯), 33(1), 54-55. (in Chinese)

Zhao SJ (赵世杰), Liu HS (刘华山), Dong XC (董新纯) (1998). Plant Physiology Experiment Guide(植物生理学实验 指导). China Agricultural Science and Technology Press, Beijing. (in Chinese)

Zhou JH(周建华)，Wang YR(王永锐) (1999)。physiological studies a poisoning effects of $\mathrm{Cd}$ and $\mathrm{Cr}$ on rice (Oryza sativa L. ) seedlings through inhibition of $\mathrm{Si}$ nutrition. Chinese Journal of Applied and Environmental Biology (应用与环境生物学报), 5(1), $11-15$. (in Chinese with English abstract) 